\title{
Doppler Ultrasound in Post-Molar Gestational Trophoblastic Neoplasia
}

\author{
Amr H. El-Shalakany ${ }^{1}$, Ghada M. Mansour ${ }^{1 *}$, Nashwa E. Hassan1, Gamal H. Sari², \\ Sahar S. Ez-Elarab ${ }^{3}$, Ibrahim Ali ${ }^{1}$ \\ ${ }^{1}$ Department of Obstetrics and Gynecology, Ain Shams University, Cairo, Egypt \\ ${ }^{2}$ Ministry of Health, Cairo, Egypt \\ ${ }^{3}$ Early Cancer Detection Unit, Maternity Hospital, Ain Shams University, Cairo, Egypt \\ Email: ^gmansour@hotmail.com, ‘gmansour@med.asu.edu.eg, *dodimansour@gmail.com
}

How to cite this paper: El-Shalakany, A.H., Mansour, G.M., Hassan, N.E., Sari, G.H., Ez-Elarab, S.S. and Ali, I. (2020) Doppler Ultrasound in Post-Molar Gestational Trophoblastic Neoplasia. Open Journal of Obstetrics and Gynecology, 10, 583-598. https://doi.org/10.4236/ojog.2020.1040052

Received: March 5, 2020

Accepted: April 23, 2020

Published: April 26, 2020

Copyright $(\odot 2020$ by author(s) and Scientific Research Publishing Inc. This work is licensed under the Creative Commons Attribution International License (CC BY 4.0).

http://creativecommons.org/licenses/by/4.0/

\begin{abstract}
Objectives: To evaluate the role of Doppler ultrasound in prediction and follow up during management of gestational trophoblastic neoplasia (GTN). Methods: The study was performed at Oncology Unit, Maternity Hospital, Ain Shams University in the period from November 2015 to December 2018. Forty cases of complete mole, after evacuation and follow up of serum human chorionic gonodotrophin ( $\beta$-hCG) titre until it reached zero level (group I) and forty post molar GTN cases (group II) were included in the study. Doppler ultrasound of the subendometrial and intramural blood flow was done for all cases of group I and II. Doppler included two dimensional and three dimensional power Doppler indices. Group II received Methotrexate (MTX) and folinic acid in a dose of 8-day MTX-FA regimen. Doppler follow up for six months of group II concurrently with the chemotherapy regimen was done. Results: A statistically significant difference was found between group I and II regarding initial readings of all Doppler parameters. Follow up for 6 months of GTN cases revealed progressive statistically significant decrease of intramural and subendometrial three dimensional power Doppler (3DPD) indices, while there was a significant increase in two dimensional (2D) Doppler parameters. Four cases were resistant to Methotrexate chemotherapy. Cut off values were determined for prediction of GTN. Multivariate analysis revealed that the most predictive parameter was the subendometrial pulsatility index $(\mathrm{PI})$, odds ratio $=10.63$ (95\% CI: $1.30-86.89)$. The cut-off point for sub-endometrial PI was: 2.05 (AUC, 90\%; sensitivity, 88\%; specificity, 76\%, PPV 78\%, and NPV 86\%) with a diagnostic accuracy of 87\%. To and Fro sign may be considered a pathognomonic intramural ultrasound sign for prediction of GTN chemo-resistance or choriocarcinoma. Conclusion: Cut off values for Doppler parameters can be used for early prediction of GTN. Doppler
\end{abstract}


ultrasound indices can be used during follow up of GTN cases concurrently with serum $\beta$-hCG to monitor the response to treatment.

\section{Keywords}

Gestational Trophoblastic Neoplasia, Methotrexate Resistance, Power

Doppler Ultrasound, Transvaginal Ultrasound

\section{Introduction}

Gestational trophoblastic disease comprises a group of disorders that are characterized by abnormal trophoblast proliferation and invasion as hydatidiform mole, invasive mole, choriocarcinoma, placental site trophoblastic tumour and epithelioid trophoblastic tumour [1].

Post-molar GTN is often curable [2], however late presentation of many cases may change the prognosis and response to chemotherapy. Although serial serum $\beta$-hCG titre measurement is considered an exceptional tumor marker for GTN, the compliance of patients differs and many cases are lost during follow up. They may develop GTN and progress to choriocarcinoma until becoming symptomatic with a late presentation. Early prediction of GTN by a non invasive method after evacuation of molar pregnancy may help in selecting the high risk group for developing GTN and encourage them to have a strict follow up.

Prediction of GTN was suggested in the literature by many authors as using post evacuation serum $\beta$-hCG level [3] [4], the slope of linear regression of $\beta$-hCG as an independent risk factor [5] [6]; placental hormones as human placental lactogen (hPL), inhibin, activin, progesterone were evaluated as tumor markers for GTN [2] and uterine artery Doppler [7].

Neoangiognesis and increased blood flow in vessels are among the criteria of malignancy. Power Doppler helps in visualizing small vessels, course of the vessels and the impedance to blood flow in these vessels. Combining of $3 \mathrm{D}$ technology with colour and power Doppler introduced better assessment of vessels, degree of vascularity and prediction of malignancy [8]. Although the pregnancy state is characterized by increased vascularity, after surgical evacuation of molar pregnancy, vascularity is expected to return to normal.

Recently, the evolution of highly equipped ultrasound machines using transvaginal approach with a high resolution, enabled the visualization of the tiny vessels of the sub endometrium and the intramural vessels, which are more descriptive and specific for the evaluation of the vascularity of the myometrium and sub endometrium more than the uterine artery blood flow assessment.

2D Doppler indices are pulsatility index (PI) and resistance index (RI). Three dimensional vascular indices are vascularization index (VI), flow index (FI), and vascularization-flow index (VFI), obtained by using virtual organ computer-aided analysis (VOCAL) and histogram modes. These 2D and 3D indices are noninvasive tools to describe vascularity of a target area of an organ [9]. 
In the current study, Doppler ultrasound was used to assess the subendometrial and intramural vascularity of post-molar GTN cases and during follow up.

\section{Aim of the Work}

To evaluate the role of Doppler ultrasound in prediction and follow up during management of gestational trophoblastic neoplasia (GTN).

\section{Patients and Methods}

The study was performed at oncology unit at maternity hospital, Ain Shams University in the period from November 2015 to December 2018. Forty cases after evacuation of complete mole and weekly measurement of serum $\beta$-hCG titre until it reached zero level (group I) and forty post-molar GTN cases (group II) were included in the study. Figure 1 is showing the original number of complete molar pregnancy included until reaching the final number of cases in groups I and II. Ethics committee approval was obtained from the department of obstetrics and gynaecology and from the ethics committee of faculty of medicine, Ain Shams University. Cases with complete mole after evacuation and signed on a written consent to share in the study were included in the study. Patients with concomitant malignancy, metastases, medical disorders, or partial mole were excluded from the study.

After diagnosis of molar pregnancy, evacuation of the uterine contents by suction evacuation was done for all cases. All cases consented for participation after explanation of all details of the study. A complete history was taken, general and local examinations were done for all cases. General examination included vital data as pulse, blood pressure, temperature and excluded jaundice, pallor or cyanosis. Serum level of $\beta$-hCG titre was obtained for all cases.

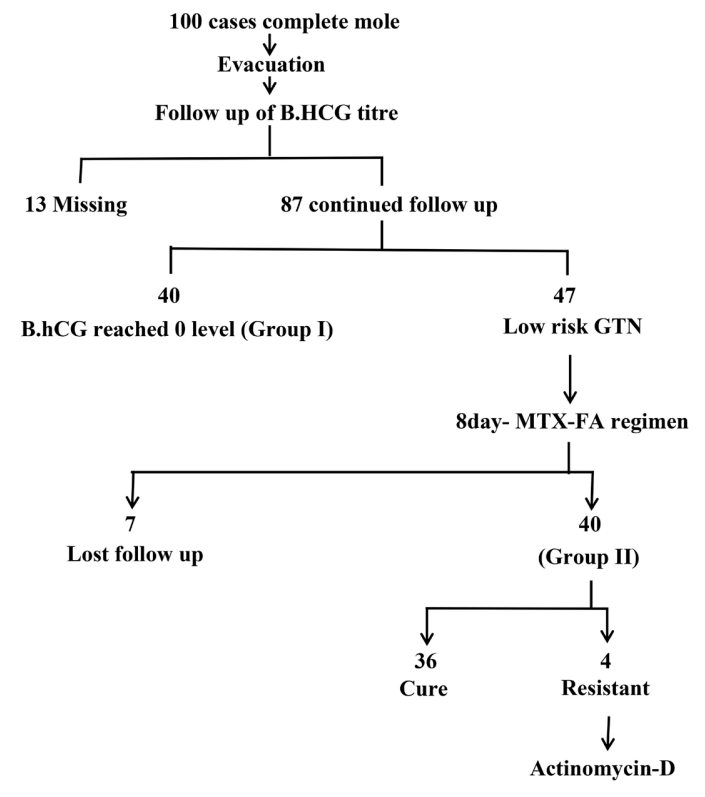

Figure 1. A flowchart of the workup of the current study. 
Transvaginal ultrasound was done, including obtaining of longitudinal, transverse and antero-posterior diameters of the uterus, assessment of the echogenicity of myometrium, measurement of endometrial thickness, assessment of adnexae as presence of theca lutein cysts and assessment of the pouch of Douglas. Two dimensional Doppler ultrasound was introduced, sample gate from subendometrial vessels obtained resistance index (RI) and pulsatility in$\operatorname{dex}(\mathrm{PI})$.

Virtual organ computer aided analysis program (VOCAL) and three dimensional power Doppler (3DPD) were introduced, the sample volume was centralized on the most vascular area of the sub endometrium and myometrium. After acquisition of the volume, 3D multiplanar view was obtained, histogram program was activated and vascular indices were calculated for the highest vascular areas of subendometrial and intramural vessels. 3DPD vascular indices obtained were: Vascularization index (VI), flow index (FI) and vascularization flow index (VFI). All ultrasound and Doppler scans were done by the same person, the second author. The ultrasound machine used was Voluson E8 Expert BT'10 GE Health-care Systems, Latin America.

All cases of GTN were classified as low-risk group according to staging and classification of FIGO committee on gynecologic oncology [10]. Follow up of Serum $\beta$-hCG titre and Doppler ultrasound indices were done every month for the next 6 months concurrently with 13 cycles of 8-day MTX-FA regimen in a dose of: MTX $1 \mathrm{mg} / \mathrm{kg} /$ day on days 1, 3, 5, 7 alternated with FA $0.1 \mathrm{mg} / \mathrm{kg}$ on days 2, 4, 6, 8, every two weeks [11] [12]. MTX resistant cases received Actinomycin-D in a dose of $1.25 \mathrm{mg}$ per square meter every two weeks (pulse Therapy) [13].

All results were recorded and tabulated. Statistical analysis was done for the results, a comparison between the initial readings of the 2 groups was done. Statistical analysis of the data during follow up of group II was done. Statistical analysis of all results was performed using the SPSS software version 15.0 (SPSS Inc., Chicago, IL, USA). Continuous variables were presented as mean and $95 \%$ confidence interval (CI). The student's $t$ test and the $\chi^{2}$ test were used for comparing continuous and categorical variables, respectively.

\section{Results}

Demographic data and initial serum $\beta$-hCG titre and Doppler results of both groups are mentioned in Table 1.

Regarding the initial subendometrial blood flow RI and PI, there was a statistically significant difference between cases of group I and group II. Mean RI and PI were lower in group II than group I, indicating higher blood flow.

Mean subendometrial RI for groups I, II successively $(0.79 \pm 0.04),(0.49 \pm$ 0.04) $(\mathrm{P}<0.001)$.

Mean subendometrial PI for groups I, II $(2.63 \pm 0.22),(1.65 \pm 0.18)(\mathrm{P}<$ $0.001)$. 
Table 1. Demographic data and initial Doppler readings of both groups after evacuation.

\begin{tabular}{|c|c|c|c|c|c|c|c|c|}
\hline & \multicolumn{4}{|c|}{ (Group I) Cases with molar pregnancy (No GTN) N $=40$} & \multicolumn{4}{|c|}{ (Group II) Post-molar GTN cases N $=40$} \\
\hline & Mean & $\pm \mathrm{SD}$ & Min & $\operatorname{Max}$ & Mean & $\pm \mathrm{SD}$ & Min & Max \\
\hline Age & 29.75 & 2.59 & 25.00 & 36.00 & 27.68 & 3.15 & 18.00 & 32.00 \\
\hline $\begin{array}{l}\text { Gestational age } \\
\text { at evacuation }\end{array}$ & 12.73 & 0.82 & 11.00 & 14.00 & 13.63 & 1.55 & 11.00 & 17.00 \\
\hline \multicolumn{9}{|l|}{ Sub-endometrial blood flow } \\
\hline Resistance index RI & 0.72 & 0.04 & 0.66 & 0.80 & 0.49 & 0.04 & 0.40 & 0.58 \\
\hline Pulsatility index PI & 2.63 & 0.22 & 2.10 & 2.90 & 1.65 & 0.18 & 1.10 & 1.90 \\
\hline Vascularization index VI & 13.94 & 0.55 & 12.80 & 15.30 & 38.25 & 1.53 & 36.80 & 43.60 \\
\hline Flow index FI & 17.13 & 2.50 & 11.80 & 21.10 & 47.64 & 1.52 & 45.80 & 52.70 \\
\hline Vascularization flow index VFI & 11.07 & 0.44 & 10.30 & 12.20 & 24.37 & 2.07 & 22.30 & 31.00 \\
\hline \multicolumn{9}{|l|}{ Myometrial (Intramural) } \\
\hline Vascularization index VI & 18.80 & 0.71 & 16.30 & 20.10 & 50.49 & 2.89 & 46.90 & 60.10 \\
\hline Flow index FI & 24.75 & 0.82 & 22.10 & 26.10 & 51.80 & 2.70 & 48.90 & 60.40 \\
\hline Vascularization flow index VFI & 10.82 & 1.99 & 4.40 & 14.20 & 26.79 & 1.11 & 25.50 & 30.10 \\
\hline B.hCG & & & & & $99,740.25$ & $20,567.02$ & $85,670.00$ & $170,000.00$ \\
\hline
\end{tabular}

There was a statistically significant difference regarding mean subendometrial VI in group I $(13.94 \pm 0.55)$ and $(38.25 \pm 1.53)$ in group II $(\mathrm{P}<0.001)$.

Mean subendometrial FI (17.13 \pm 2.5$)$ in group I ( $47.64 \pm 1.52)$ in group II (P $<0.001)$ and mean subendometrial VFI $(11.07 \pm 0.44)$ and $(24.37 \pm 2.07)$ in group II $(\mathrm{P}<0.001)$. All 3DPD indices of subendometrial blood flow revealed higher values in group II (GTN group) than group I.

There was a statistically significant difference regarding mean intramural VI, $(18.80 \pm 0.71)$ in group I and $(50.49 \pm 2.89)$ in group II $(\mathrm{P}<0.001)$, mean intramural FI $(24.75 \pm 0.82)$ in group I and $(51.80 \pm 2.70)$ in group II $(\mathrm{P}<0.001)$ and mean intramural VFI $(10.82 \pm 1.99)$ in group I and $(26.79 \pm 1.11)$ in group II (P $<0.001)$ All 3DPD indices of intramural blood flow revealed higher values in group II (GTN group) than group I.

In 6 months follow up of GTN cases, there was a statistically significant increase in sub-endometrial RI and PI (Figure 2(a)). While the Sub-endometrial VI, FI, and VFI revealed a significant decrease (Figure 2(b)) in comparison with the initial values $(\mathrm{P}<0.001)$.

Intramural VI and VFI showed significant decrease in the mean values of post-molar GTN cases along follow-up period in comparison to the initial reading $\mathrm{P}<0.001$. While the intramural FI showed a significant decrease after $3^{\text {rd }}, 4^{\text {th }}$, $5^{\text {th }}$ and $6^{\text {th }}$ month in comparison to the initial reading $\mathrm{P}<0.001$, but non-significant change after $1^{\text {st }}$ and $2^{\text {nd }}$ month $\mathrm{P}>0.05$ (Figure $2(\mathrm{c})$ ).

There was a significant decrease in the mean values of serum $\beta$-hCG titre in the post-molar GTN cases during the follow-up period (Figure $2(\mathrm{~d})$ ) in comparison to the initial readings $(\mathrm{P}<0.001)$. 
In all cases of GTN, the activated 3DPD view revealed chaotic distribution of blood vessels in the myometrium. Doppler ultrasound pictures (Figures 3(a)-(f)).

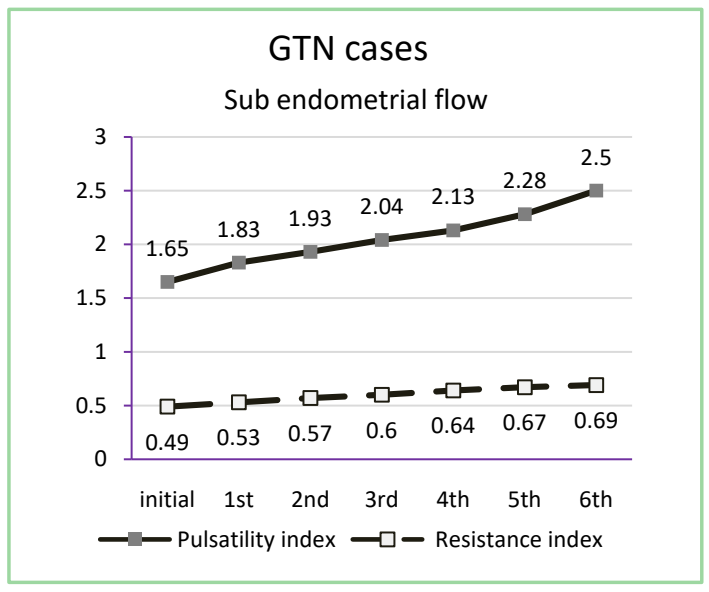

(a) Mean subendometrial blood flow PI and RI.

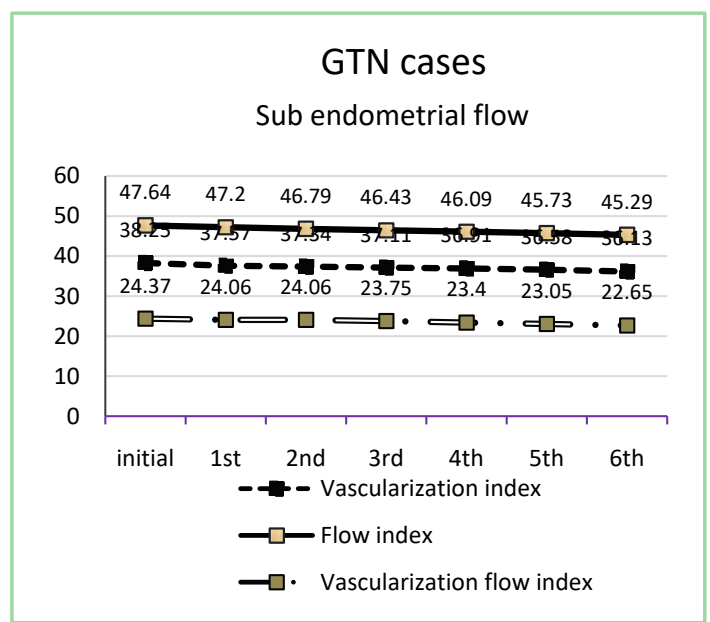

(b) Mean Subendometrial blood flow VI, FI, and VFI.

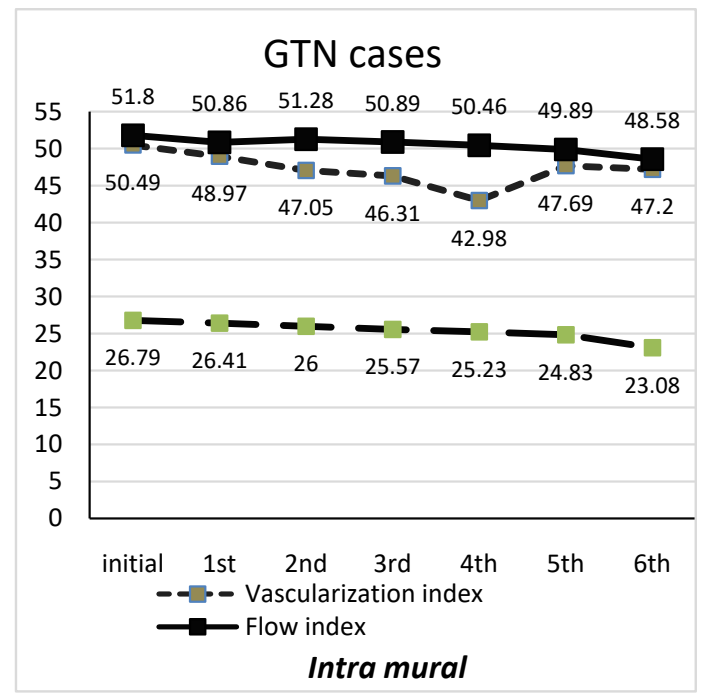

(c) Mean intramural blood flow VI, FI and VFI. 


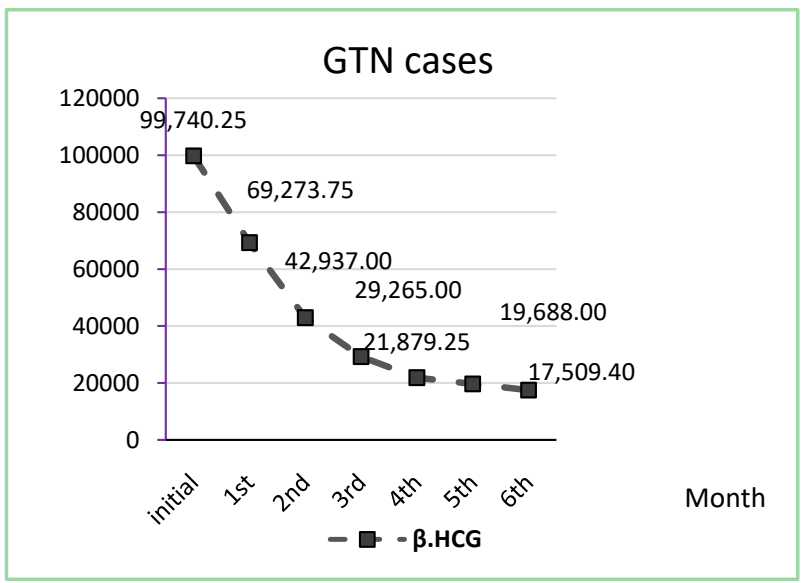

(d) Mean serum B.hCG titre.

Figure 2. Means of all results in 6 months follow up of GTN cases: (a) Subendometrial blood flow RI and PI, (b) Subendometrial blood flow VI, FI and VFI, (c) Intramural VI, FI and VFI, (d) Serum B. HCG titre.

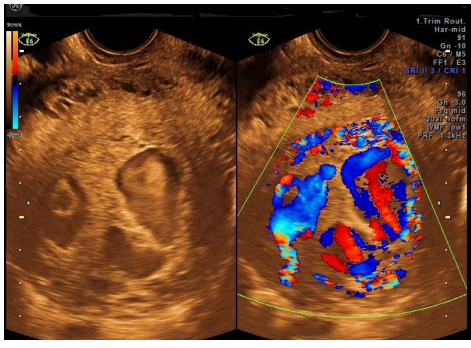

(a)

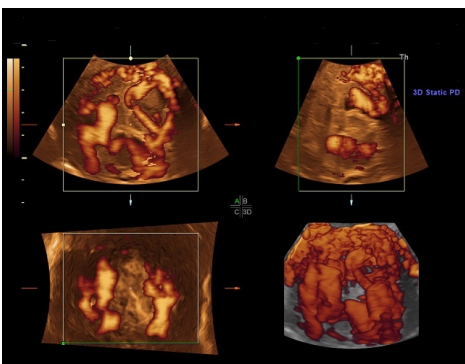

(c)

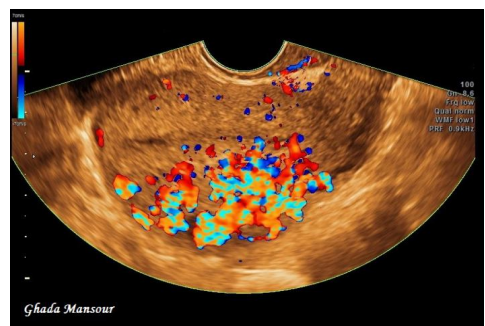

(e)

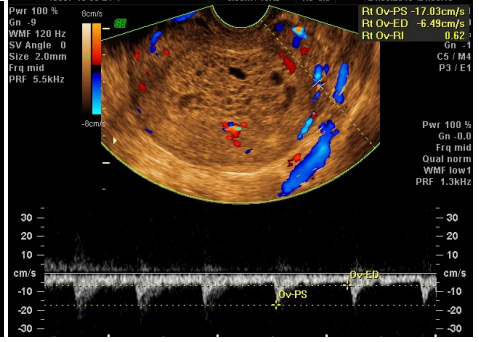

(b)

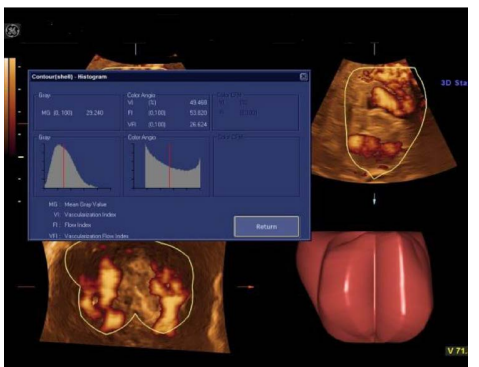

(d)

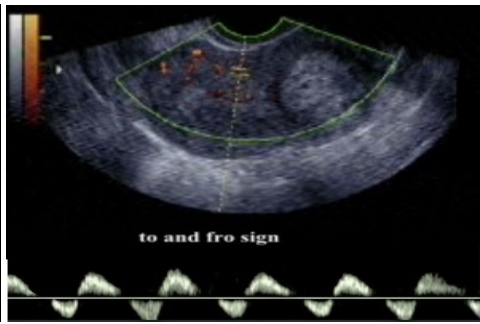

(f)

Figure 3. Doppler ultrasound: (a) A case of GTN before and after introduction of Doppler ultrasound at the intramural area; (b) Before evacuation of molar pregnancy; (c) 3DPD of a GTN case showing the chaotic pattern, multiplanar view box A activated; (d) Histogram and VOCAL activation and 3D vascular indices: VI, FI and VFI; (e) Resistant GTN case; (f) To and fro Doppler sign in a resistant case. 
Four MTX resistant GTN cases received Actinomycin-D regimen as a second line single agent treatment.

Using Pearson correlation coefficient $r$, there was a statistically positive correlation (strong association) between $\beta$ HCG titre and subendometrial VI, FI, VFI, intramural VI, FI, VFI $(\mathrm{P}<0.001)$ and negative correlation between HCG and sub endometrial RI, and PI $(\mathrm{P}<0.001)$.

Comparing the Doppler readings between $1^{\text {st }}$ and $2^{\text {nd }}, 2^{\text {nd }}$ and $3^{\text {rd }}, 3^{\text {rd }}$ and $4^{\text {th }}$, $4^{\text {th }}$ and $5^{\text {th }}, 5^{\text {th }}$ and $6^{\text {th }}$ month, there was a significant increase in sub-endometrial RI and PI. While sub-endometrial VI, FI and VFI showed significant decrease P $<0.001$.

As regards intramural VI, there was a significant decrease between $1^{\text {st }}$ and $2^{\text {nd }}$, $2^{\text {nd }}$ and $3^{\text {rd }}, 4^{\text {th }}$ and $5^{\text {th }}, 5^{\text {th }}$ and $6^{\text {th }}$ month $(\mathrm{P}<0.001)$ but non significant change between $3^{\text {rd }}$ and $4^{\text {th }}$ month $(\mathrm{P}=0.16)$. In addition, Intramural VFI showed significant decrease between, $2^{\text {nd }}$ and $3^{\text {rd }}, 3^{\text {rd }}$ and $4^{\text {th }}, 4^{\text {th }}$ and $5^{\text {th }}, 5^{\text {th }}$ and $6^{\text {th }}$ month $(\mathrm{P}$ $<0.001)$ but non-significant decrease between $1^{\text {st }}$ and $2^{\text {nd }}$ month $(P=0.50)$. Finally, intramural VFI showed significant decrease between the reading of $1^{\text {st }}$ and $2^{\text {nd }}, 2^{\text {nd }}$ and $3^{\text {rd }}, 3^{\text {rd }}$ and $4^{\text {th }}, 4^{\text {th }}$ and $5^{\text {th }}, 5^{\text {th }}$ and $6^{\text {th }}$ month $(\mathrm{P}<0.001)$.

Regarding means of serum $\beta$-.hCG levels, there was a significant decrease between the successive readings between each month of follow up and the next one $(\mathrm{P}<0.001)$.

Cases with GTN showed significant lower mean subendometrial RI on follow-up at $1^{\text {st }}, 2^{\text {nd }}, 3^{\text {rd }}, 4^{\text {th }}$, and $5^{\text {th }}$ months than molar cases with no GTN (P < 0.001 ) but after 6 months it reached nearly mean level of cases with no GTN and showed non-significant difference $(P=0.13)$.

Cases with GTN showed significant lower mean subendometrial PI on follow-up at $1^{\text {st }}, 2^{\text {nd }}, 3^{\text {rd }}, 4^{\text {th }}$, and $5^{\text {th }}$ month than cases with no GTN P $<0.001$ but after 6 months, it reached nearly mean level of molar cases with no GTN and showed non-significant difference $(\mathrm{P}=0.09)$.

While mean subendometrial VI, FI, VFI, and intramural VI, FI VFI remained higher in GTN cases (group II) than group I $(\mathrm{P}<0.05)$.

Regarding the changes between the values of Methotrexate responsive and Methotrexate resistant cases of group II, responsive cases after $5^{\text {th }}$ and $6^{\text {th }}$ month reached a lower level near to mean value of sub RI and PI of molar cases ( $P>$ 0.05), other values showed significant difference between Methotrexate responsive and molar cases $(\mathrm{P}<0.001)$ and Methotrexate resistant cases showed significantly different values from molar cases in all the variables measured $(\mathrm{P}<$ 0.001).

ROC curves were used to determine cut off values for prediction of GTN, for subendometrial RI, PI, VI, FI and VFI, while Intramural indices were not significant for prediciton of GTN. ROC curves were used for determining a cut off value of serum $\beta$-hCG for prediction of GTN and another cut off value for prediction of chemo resistance (Figure 4 ) on multivariate analysis, the most predictive parameter was the subendometrial PI odds ratio $=10.63$ (95\% CI: 1.30 86.89). 
ROC Curve

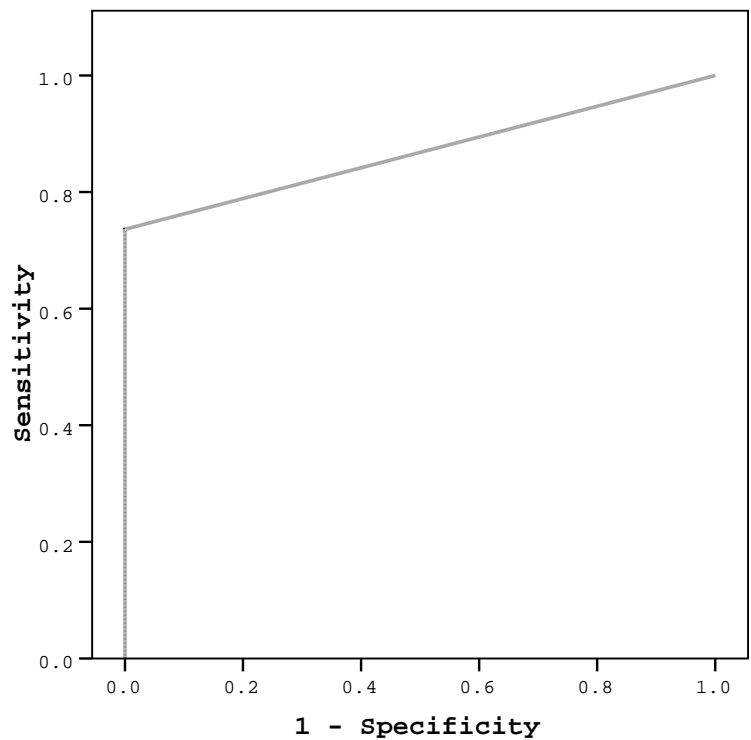

(a) Mean Serum B.hCG of 80 cases (groups I, II)

\begin{tabular}{cccc}
\hline Area under the curve & Std. Error & $\mathrm{P}$ & 95\% Confidence Interval \\
\hline 0.87 & 0.03 & $<0.001$ & $0.80-0.93$
\end{tabular}

The cut-off point HCG was 42,835 (AUC, 1.00; sensitivity, 73\%; specificity, 100\%, PPV 100\%, and NPV $79 \%)$ with a diagnostic accuracy of $86 \%$.

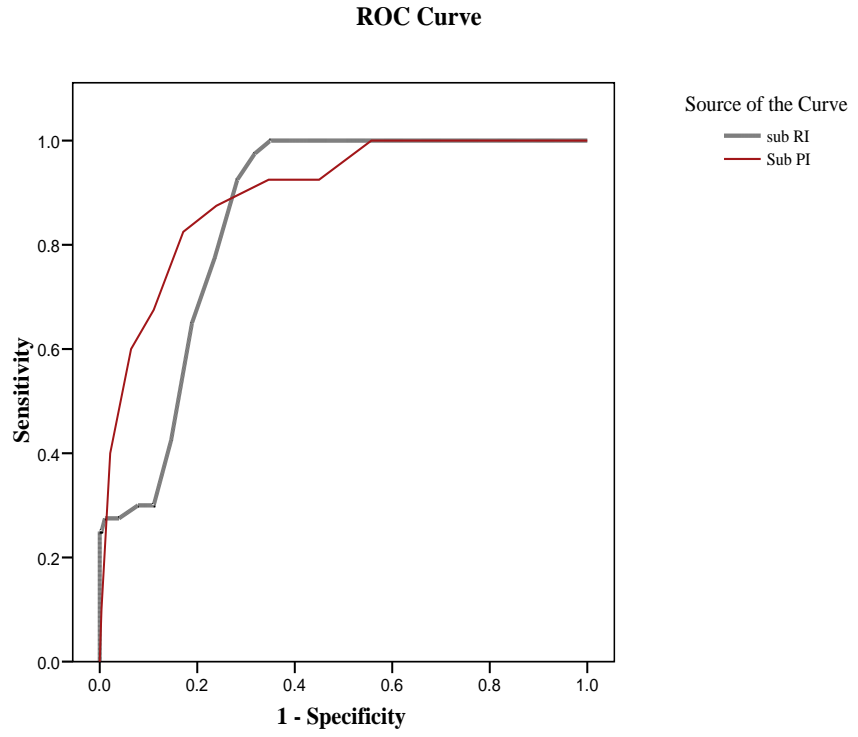

(b) Mean Subendometrial blood flow PI and RI

\begin{tabular}{ccccc}
\hline Variable(s) & Area under the curve & Std. Error & $\mathrm{P}$ & 95\% Confidence Interval \\
\hline sub RI & 0.86 & 0.02 & $<0.001$ & $0.81-0.90$ \\
Sub PI & 0.90 & 0.02 & $<0.001$ & $0.85-0.94$ \\
\hline
\end{tabular}

The cut-off point for Sub RI were 0.66 (AUC, $80 \%$; sensitivity, $97.5 \%$; specificity, 68\%, PPV 75\%, and NPV 97\%) with a diagnostic accuracy of $97 \%$. The cut-off point for Sub PI were 2.05 (AUC, 90\%; sensitivity, 88\%; specificity, $76 \%$, PPV $78 \%$, and NPV $86 \%$ ) with a diagnostic accuracy of $87 \%$. 


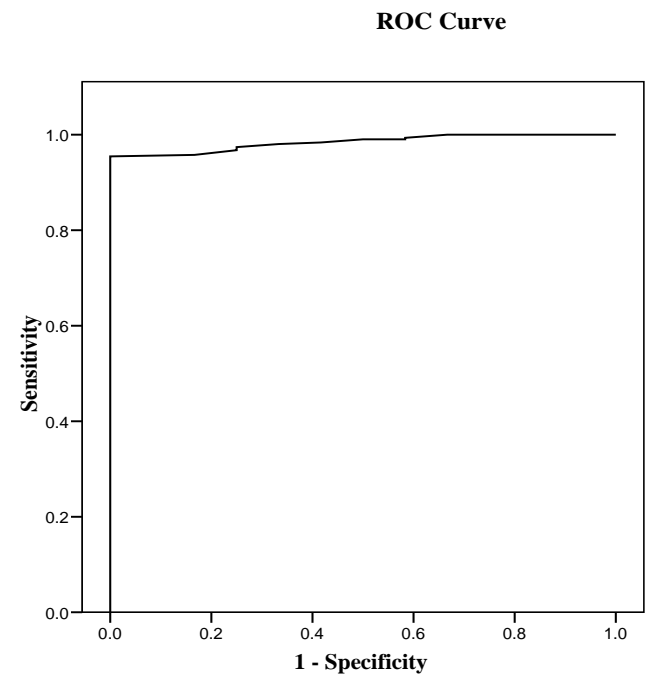

(c) Mean serum B.hCG titre in GTN cases.

\begin{tabular}{ccccc}
\hline Variable & AUC & Std. Error & P & 95\% Confidence Interval \\
\hline BhCG & 0.98 & 0.007 & $<0.001$ & $0.97-0.99$ \\
\hline
\end{tabular}

The cut-off point HCG was 147,500 (AUC, 98\%; sensitivity, 97\%; specificity, 75\%, PPV 76\%, and NPV 97\%) with a diagnostic accuracy of $86 \%$.

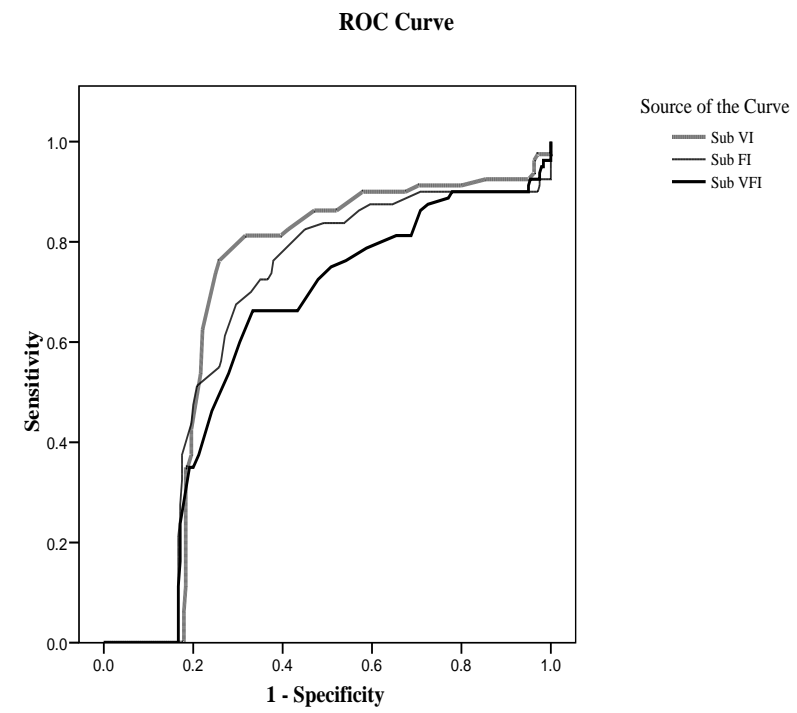

(d) Mean Subendometrial blood flow VI, FI and VFI.

\begin{tabular}{ccccc}
\hline Variable & AUC & Std. Error & $\mathrm{P}$ & 95\% Confidence Interval \\
\hline Sub VI & 0.70 & 0.03 & $<0.001$ & $0.63-0.76$ \\
Sub FI & 0.67 & 0.04 & $<0.001$ & $0.60-0.74$ \\
Sub VFI & 0.62 & 0.04 & $<0.001$ & $0.60-0.74$ \\
\hline
\end{tabular}

Area under the curve AUC) were less than $75 \%$, so the ability of the tests to correctly classify those with and without the disease is poor.

Figure 4. ROC curves (a) Mean serum B.hCG titre in all cases for prediction of GTN; (b) Mean subendometrial RI and PI for prediction of GTN; (c) Mean serum B.hCG titre for prediction of MTX resistance in GTN cases; (d) Mean subendometrial VI, FI, VFI for prediction of GTN (Non significant). 


\section{Discussion}

Elevated serum B-hCG level, previous history of hydatidiform mole and various demographic factors were related to the incidence of GTN [14]-[19]. Some studies discussed prediction of GTN using statistically significant parameters [2]-[7].

In the current study, Doppler ultrasound was used during follow up of post molar GTN cases and was used to predict GTN using cut off values for each parameter.

In agreement with the current study, Wang et al., in fifty two gestational trophoblastic disease GTD cases found that, clinical features, sonography and 3DPD were helpful in diagnosing GTD, distinguishing the invasive nature, detecting recurrence, and assessing the effectiveness of the chemotherapy [20], but did not assess the value of Doppler in prediction of GTN or MTX resistance as in the current study. Recurrence assessment was not included in plan of the current study.

Emoto et al., used contrast-enhanced Doppler in twenty three patients in their study and stated that it may be useful in differentiating invasive or malignant GTDs from noninvasive GTDs [21]. Considering the non invasive purpose for prediction of GTN in the current study, enhancement was not preferred and also to avoid any unneeded anaphylaxis that may occur. 3DPD was used in the current study, while it was not used in Emoto et al., so the pattern of vascularity which reflects neongiogenesis phnomenon in GTN was not investigated in their study as the current one.

The significant correlations between serum $\beta$-hCG titre and different Doppler parameters found in the current study prove the linear changes in blood flow with the response to chemotherapy.

According to the results of the current study, chemotherapy had a significant inverse correlation with RI and PI as it reached lower level after 6 months. Multivariate analysis revealed that PI was the most accurate predictive for GTN. 3DPD indices were not affected by chemotherapy the same as the $2 \mathrm{D}$ indices that may be explained by the fact that 3DPD indices and chaotic pattern of vessels would not rapidly change with MTX treatment, while the blood flow which was reflected mainly by 2D Doppler indices was more rapidly affected.

The neoangiogenesis phenomenon depicted as a chaotic pattern by 3DPD was an indicator for the GTN but follow up of response to treatment depended mainly on decreasing flow in vessels rather than a decrease in number or pattern of distribution of vessels. It seems that the chaotic pattern needs a longer time to decrease or disappear in cured GTN cases.

Uterine artery pulsatility index was introduced in the literature with gestational trophoblastic tumors (GTTs) for the assessment of GTD [22], prediction of post-molar GTN [14] or as predictive of methotrexate resistance (MTX-R) [7]. In the current study, subendometrial and intramural vessels were used which are the specific vessels directly related and feeding the GTN. 
Park et al., studied use of Doppler ultrasound with color flow in twenty six patients in management of malignant trophoblastic tumors. In agreement with the current study, they concluded that color flow mapping Doppler ultrasound can be useful in the diagnosis and monitoring of the treatment of malignant trophoblastic tumors along with the conventional serum B-hCG. Larger sample size, use of 3DPD and assessment of the very small arteries in the subchorionic space and myometrium was done in the current study [23].

The same for Oguz et al., they concluded that transvaginal color Doppler sonography offers a non-invasive technique for estimation of blood flow patterns, with the potential of characterizing tumor, through the differences in blood flow patterns. Thirty seven patients were treated with a single agent chemotherapy; methotrexate [17]. They found a statistically significant difference in Doppler ultrasound in differentiation between invasive GTD \& noninvasive GTD but did not mention cut off values for prediction of GTN by Doppler parameters.

Malek, et al., mentioned the Complementary Role of Ultrasound in Management of Gestational Trophoblastic Disease [24]. Many authors reported the importance of power Doppler ultrasound quantification to be used as a non-invasive assessment of tumour vascularity and can distinguish low-risk GTN patients who become chemo resistant from those who have an uncomplicated course with first line treatment [14] [25]. Epstein and Joneborg, discussed the sonograhpic morphology of GTN and in Methotrexate resistant cases [26]. They did not mention indices or cut off values for prediction of GTN by Doppler and depended in the sonographic morphological assessment on size of lesion, which is usually a late sign for diagnosis, Doppler of tiny vessels of the sub endomtrium and myometrium used in the current study is an earlier predictor for the disease.

Cavoretto, et al. discussed the chemo-resistance of GTN cases, which depended mainly on the basis of hCG curve, they wanted to identify those cases who can achieve resolution by continuing mthotrexate treatment despite a transient hCG plateau. They used subjective methods for ultrasound and Doppler criteria depending on echogenicity and degree of vascularity. In the current study indices were used and cut off values were determined for prediction of GTN and for chemo resistance [27]. Chemo-resistance can be due to mixed gestational trophoblastic neoplasia (GTN) which is a rare occurrence that refers to the coexistence of choriocarcinoma and/or placental site trophoblastic tumor and/or epithelioid trophoblastic tumor. Diagnosis and management of mixed GTN are challenging as was mentioned by Kong, et al. [28]. Prediction of GTN and its assessment by serum $\beta$-hCG levels, slope or 2 weeks readings [29]-[35], all need time, while in the current study a post-evacuation single Doppler reading is suggested as a non invasive predictor for GTN.

In the current study, results are for complete mole cases only while partial mole cases were not included and number of MTX resistant cases was not statistically satisfactory for further analysis; factors considered as limitations of the study. To and fro Doppler sign and turbulent intramural blood flow were de- 
picted in all chemo-resistant GTN cases. That sign may be a sonographic pathognomonic sign for chemo-resistance or choriocarcinoma. Further studies with larger numbers are needed to corroborate that finding.

According to the results of the current study, Doppler ultrasound as a non-invasive technique can be used for prediction of GTN in molar cases and can be used during follow up of treatment of cases of GTN to monitor the response to chemotherapy. Proper Prediction of GTN in the proper time may accelerate the management and hence decrease the number of resistant cases to chemotherapy.

\section{Conflicts of Interest}

The authors declare no conflicts of interest regarding the publication of this paper.

\section{References}

[1] Jiang, F., Wan, X.R., Xu, T., Feng, F.Z., Ren, T., Yang, J.J., Zhao, J., Yang, T. and Xiang, Y. (2018) Evaluation and Suggestions for Improving the FIGO 2000 Staging Criteria for Gestational Trophoblastic Neoplasia: A Ten-Year Review of $1420 \mathrm{~Pa}-$ tients. Gynecologic Oncology, 149, 539-544.

https://doi.org/10.1016/j.ygyno.2018.04.001

[2] Seki, K., Matsui, H. and Sekiya, S. (2004) Advances in the Clinical Laboratory Detection of Gestational Trophoblastic Disease. Clinica Chimica Acta, 349, 1-13. https://doi.org/10.1016/j.cccn.2004.04.027

[3] Kang, W.D., Choi, H.S. and Kim, S.M. (2012) Prediction of Persistent Gestational Trophobalstic Neoplasia: The Role of hCG Level and Ratio in 2 Weeks after Evacuation of Complete Mole. Gynecologic Oncology, 124, 250-253.

https://doi.org/10.1016/j.ygyno.2011.10.035

[4] Trommel, N.E.V., Sweep, F.C.G.J., Schijf, C.P.T., Massuger, L.F.A.G. and Thomas, C.M.G. (2005) Diagnosis of Hydatidiform Mole and Persistent Trophoblastic Disease: Diagnosis Accuracy of Total Human Chorionic Gonadotropin (hCG), Free hCG $\alpha$ - and $\beta$-Subunits, and Their Ratios. European Journal of Endocrinology, 153, 565-575. https://doi.org/10.1530/eje.1.01997

[5] Bakhtiyari, M., Mirzamoradi, M., Kimyaiee, P., Aghaie, A., Mansournia, M.A., Ashrafi-Vand, S. and Sarfjoo, F. (2015) Postmolar Gestational Trophoblastic Neoplasia: Beyond the Traditional Risk Factors. Fertility and Sterility, 104, 649-654. https://doi.org/10.1016/j.fertnstert.2015.06.001

[6] Lybol, C., Sweep, F.C., Ottevanger, P.B., Massuger, L.F. and Thomas, C.M. (2013) Linear Regression of Postevacuation Serum Human Chorionic Gonadotropin Concentrations Predicts Postmolar Gestational Trophoblastic Neoplasia. International Journal of Gynecological Cancer, 23, 1150-1156. https://doi.org/10.1097/IGC.0b013e31829703ea

[7] Agarwal, R., Strickland, S., McNeish, I.A., Patel, D.C., Foskett, M., Boultbee, J.E., Newlands, E.S. and Seckl, M.J. (2002) Doppler Ultrasonography of the Uterine Artery and the Response to Chemotherapy in Patients with Gestational Trophoblastic Tumors. Clinical Cancer Research, 8, 1142-1147.

[8] Shi, H., Wang, H., Wang, Y., Zhao, H., Xv, N., Liu, F. and Peng, X. (2016) Three-Dimensional Color Power Doppler as an Imaging Technique in Cancer. In- 
ternational Journal of Clinical and Experimental Medicine, 9, 9781-9790.

[9] Martins, W. (2010) Three-Dimensional Power Doppler: Validity and Reliability. Ultrasound in Obstetrics \& Gynecology, 36, 530-533. https://doi.org/10.1002/uog.8836

[10] FIGO Committee on Gynecologic Oncology (2009) Current FIGO Staging for Cancer of the Vagina, Fallopian Tube, Ovary, and Gestational Trophoblastic Neoplasia. International Journal of Gynecology \& Obstetrics, 105, 3-4. https://doi.org/10.1016/j.ijgo.2008.12.015

[11] Braga, A., de Souza Hartung Araújo, C., Mora, P.A.R., Paulino, E., de Melo, A.C., Velarde, G.C., Dos Santos Esteves, A.P.V., Junior, J.A., Filho, J.R., Elias, K.M., Horowitz, N.S. and Berkowitz, R.S. (2020) Comparison of Treatment for Low-Risk GTN with Standard 8-Day MTX/FA Regimen versus Modified MTX/FA Regimen without Chemotherapy. Gynecologic Oncology, 156, 598-605.

https://doi.org/10.1016/j.ygyno.2019.12.044

[12] Mangili, G., Cioffi, R., Danese, S., Frigerio, L., Ferrandina, G., Cormio, G., Rabaiotti, E., Scarfone, G., Gadducci, A., Bergamini, A., Pisano, C. and Candiani, M. (2018) Does Methotrexate (MTX) Dosing in a 8-Day MTX/FA Regimen for the Treatment of Low-Risk Gestational Trophoblastic Neoplasia Affect Outcomes? The MITO-9 Study. Gynecologic Oncology, 151, 449-452. https://doi.org/10.1016/j.ygyno.2018.09.025

[13] Maestá, I., Nitecki, R., Desmarais, C.C.F., Horowitz, N.S., Goldstein, D.P., Elias, K.M. and Berkowitz, R.S. (2020) Effectiveness and Toxicity of Second-Line Actinomycin D in Patients with Methotrexate-Resistant Postmolar Low-Risk Gestational Trophoblastic Neoplasia. Gynecologic Oncology. https://doi.org/10.1016/j.ygyno.2020.02.001

[14] Asmar, F.C., Braga-Neto, A.R., Filho, J.R., Villas-Boas, J.M.S., Charry, R.C. and Maesta, I. (2017) Uterine Artery Doppler Flow Velocimetry Parameters for Predicting Gestational Trophoblastic Neoplasia after Complete Hydatidiform Mole, a Prospective Cohort Study. Clinics (Sao Paulo), 72, 284-288. https://doi.org/10.6061/clinics/2017(05)05

[15] Ngan, H.Y., Kohorn, E.I., Cole, L.A., Kurman, R.J., Kim, S.J., Lurain, J.R., et al. (2012) Trophoblastic Disease. International Journal of Gynecology \& Obstetrics, 119, S130-S136. https://doi.org/10.1016/S0020-7292(12)60026-5

[16] Savage, P.M., Sita-Lumsden, A., Dickson, S., Iyer, R., Everard, J., Coleman, R., Fisher, R.A., Short, D., Casalboni, S., Catalano, K. and Seckl, M.J. (2013) The Relationship of Maternal Age to Molar Pregnancy Incidence, Risks for Chemotherapy and Subsequent Pregnancy Outcome. Journal of Obstetrics and Gynaecology, 33, 406-411. https://doi.org/10.3109/01443615.2013.771159

[17] Ogouz, S., Sargin, A., Aytan, H., Kelekci, S. and Dumanli, H. (2004) Doppler Study of Myometrium in Invasive Gestational Trophoblastic Disease. International Journal of Gynecological Cancer, 14, 972-979. https://doi.org/10.1136/ijgc-00009577-200409000-00034

[18] Ayhan, A., Utku Dogan, N. and Dursun, P. (2014) Oncofrtility for Gynecologic and Non-Gynecologic Cancers: Fertility Sparing in Young Women of Reproductive Age. Critical Reviews in Oncoloogy/ Hematology, 92, 258-267. https://doi.org/10.1016/j.critrevonc.2014.07.001

[19] Kohorn, E.I. (2012) Imaging Practices in the Diagnosis and Management of Gestational Trophoblastic Disease: An Assessment. Journal of Reproductive Medicine, 57, 207-210. 
[20] Wang, W., Tian, X., Zhang, T., Wang, Y., Han, Z. and An, R. (2015) Characteristics of Three-Dimensional Power Doppler in Gestational Trophoblastic Disease. Disease Markers, 2015, Article ID: 917687. https://doi.org/10.1155/2015/917687

[21] Emoto, M., Sadamori, R., Hachisuga, T., Kawarabayashi, T. and Miyamoto, S. (2011) Clinical Usefulness of Contrast-Enhanced Color Doppler Ultrasonography in Invasive and Noninvasive Gestational Trophoblastic Diseases: A Preliminary Study. Journal of Reproductive Medicine, 56, 224-234.

[22] Yalcin, O.T., Ozalp, S.S. and Tanir, H.M. (2002) Assessment of Gestational Trophoblastic Disease by Doppler Ultrasonography. European Journal of Obstetrics \& Gynecology and Reproductive Biology, 103, 83-87. https://doi.org/10.1016/S0301-2115(02)00026-X

[23] Park, T.K., Kim, S.N. and Lee, S.K. (1996) Analysis of Risk Factors for Postmolar Trophoblastic Disease: Categorization of Risk Factors and Effect of Prophylactic Chemotherapy. Yonsei Medical Journal, 37, 412. https://doi.org/10.3349/ymj.1996.37.6.412

[24] Malek, M., Moradi, B., Mousavi, A.S., Ahmadinejad, N., Kazemi, M.A. and Gity, M. (2015) Complementary Role of Ultrasound in Management of Gestational Trophoblastic Disease. Iranian Journal of Radiology, 12, e13955. https://doi.org/10.5812/iranjradiol.13955

[25] Lin, L.H., Bernardes, L.S., Hase, E.A., Fushida, K. and Francisco, R.P. (2015) Is Doppler Ultrasound Useful for Evaluating Gestational Trophoblastic Disease? Clinics, 70, 810-815. https://doi.org/10.6061/clinics/2015(12)08

[26] Epstein, E. and Joneborg, U. (2020) Sonographic Characteristics of Post-Molar Gestational Trophoblastic Neoplasia at Diagnosis and during Follow-Up, and Its Relation to Methotrexate Resistance. Ultrasound in Obstetrics \& Gynecology. https://doi.org/10.1002/uog.21971

[27] Cavoretto, P., Gentile, C., Mangili, G., Garavaglia, E., Valsecchi, L., Spagnolo, D., Montoli, S. and Candiani, M. (2012) Transvaginal Ultrasound Predicts Delayed Response to Chemotherapy and Drug Resistance in Stage I Low-Risk Trophoblastic Neoplasia. Ultrasound in Obstetrics \& Gynecology, 40, 99-105. https://doi.org/10.1002/uog.11097

[28] Kong, Y., Tao, G., Zong, L., Yang, J., Wan, X., Wang, W. and Xiang, Y. (2019) Diagnosis and Management of Mixed Gestational Trophoblastic Neoplasia: A Study of 16 Cases and a Review of the Literature. Frontiers in Oncology, 9, 1262. https://doi.org/10.3389/fonc.2019.01262

[29] Burny, C., Rabilloud, M., Golfier, F., Massardier, J., Hajri, T., Schott, A.M. and Subtil, F. (2016) Early Diagnosis of Gestational Trophoblastic Neoplasia Based on Trajectory Classification with Compartment Modeling. BMC Medical Research Methodology, 16, 3. https://doi.org/10.1186/s12874-015-0106-y

[30] Soper, J.T. (2006) Gestational Trophoblastic Disease. Obstetrics \& Gynecology, 108, 176-187. https://doi.org/10.1097/01.AOG.0000224697.31138.a1

[31] Schmitt, C., Doret, M., Massardier, J., Hajri, T., Schott, A.M., Raudrant, D., et al. (2013) Risk of Gestational Trophoblastic Neoplasia after hCG Normalisation According to Hydatidiform Mole Type. Gynecologic Oncology, 130, 86-89. https://doi.org/10.1016/j.ygyno.2013.03.010

[32] Wolfberg, A.J., Feltmate, C., Goldstein, D.P., Berkowitz, R.S. and Lieberman, E. (2004) Low Risk of Relapse after Achieving Undetectable HCG Levels in Women with Complete Molar Pregnancy. Obstetrics \& Gynecology, 104, 551-554. https://doi.org/10.1097/01.AOG.0000136099.21216.45 
[33] Kohorn, E.I. (2001) The New FIGO 2000 Staging and Risk Factor Scoring System for Gestational Trophoblastic Disease: Description and Critical Assessment. International Journal of Gynecological Cancer, 11, 73-77.

https://doi.org/10.1046/j.1525-1438.2001.011001073.x

[34] Schoeberl, M.R. (2007) A Model for the Behavior of Beta-hCG after Evacuation of Hydatidiform Moles. Gynecologic Oncology, 105, 776-779. https://doi.org/10.1016/j.ygyno.2007.02.021

[35] You, B., Pollet-Villard, M., Fronton, L., Labrousse, C., Schott, A.M., Hajri, T., et al. (2010) Predictive Values of hCG Clearance for Risk of Methotrexate Resistance in Low-Risk Gestational Trophoblastic Neoplasias. Annals of Oncology, 21, 1643-1650. https://doi.org/10.1093/annonc/mdq033 